SCORING System for the ANTIBIOtic-Use Screening Evaluation (ABUSE) For PATIENTS

\begin{tabular}{lll}
\hline Total Score & $\begin{array}{c}\text { Patlent/Careglver } \\
\text { ABusE Rating }\end{array}$ & Notes \\
\hline $0-50$ & \multicolumn{1}{c}{ (Antlblotic-Abstaining Angels) } & \\
$55-120$ & Excellent & Candidate for sainthood \\
$125-200$ & Good & Model citizen \\
$205-300$ & Fair & Occasional abuser \\
$305-455$ & Poor & Frequent abuser \\
$460-600$ & Bad & Habitual abuser \\
& Awful & Antibiotic addict and dealer \\
\hline
\end{tabular}

(Drug-Dependent Devlls)

\title{
Reminder Systems Improve Immunization Rates
}

Gina Pugliese, RN, MS

Martin S. Favero, PhD

Immunization rates for children and adults remain below national goals. While experts recommend that healthcare professionals remind patients of needed immunizations, few practitioners actually use reminders. Little is known about the effectiveness of reminders in different settings or patient populations. Szilagyi and colleagues reported on a literature review to assess the effectiveness of patient reminder systems in improving immunization rates and to compare the effectiveness of different types of reminders for a variety of patient populations.

The search was performed using MEDLINE, EMBASE, PsychINFO, Sociological Abstracts, and $C A B$ Health Abstracts. Relevant articles, as well as pub- lished abstracts, conference proceedings, and files of study collaborators, were searched for relevant references.

English-language studies involving patient reminder/recall interventions were eligible for review if they involved randomized controlled trials, controlled before-after studies, or interrupted time series, and measured immunization rates. Of 109 studies identified, 41 met eligibility criteria. Patient reminder systems were effective in improving immunization rates in $33(80 \%)$ of the 41 studies, irrespective of baseline immunization rates, patient age, setting, or vaccination type. Increases in immunization rates due to reminders ranged from 5 to 20 percentage points. Reminders were effective for childhood vaccinations, childhood influenza vaccinations, adult pneumococcus or tetanus vaccinations, and adult influenza vaccinations. While reminders were most effective in academic settings, they were also highly effective in private practice settings and public health clinics. All types of reminders were effective (postcards, letters, and telephone or autodialer calls), with telephone reminders being most effective but costliest.

The authors concluded that patient reminder systems in primary-care settings are effective in improving immunization rates. Primary-care physicians should use patient reminders to improve immunization delivery.

FROM: Szilagyi PG, Bordley C, Vann JC, Chelminski A, Kraus RM, Margolis PA, et al. Effect of patient reminder/recall interventions on immunization rates: a review. JAMA 2000;284:1820-1827. 

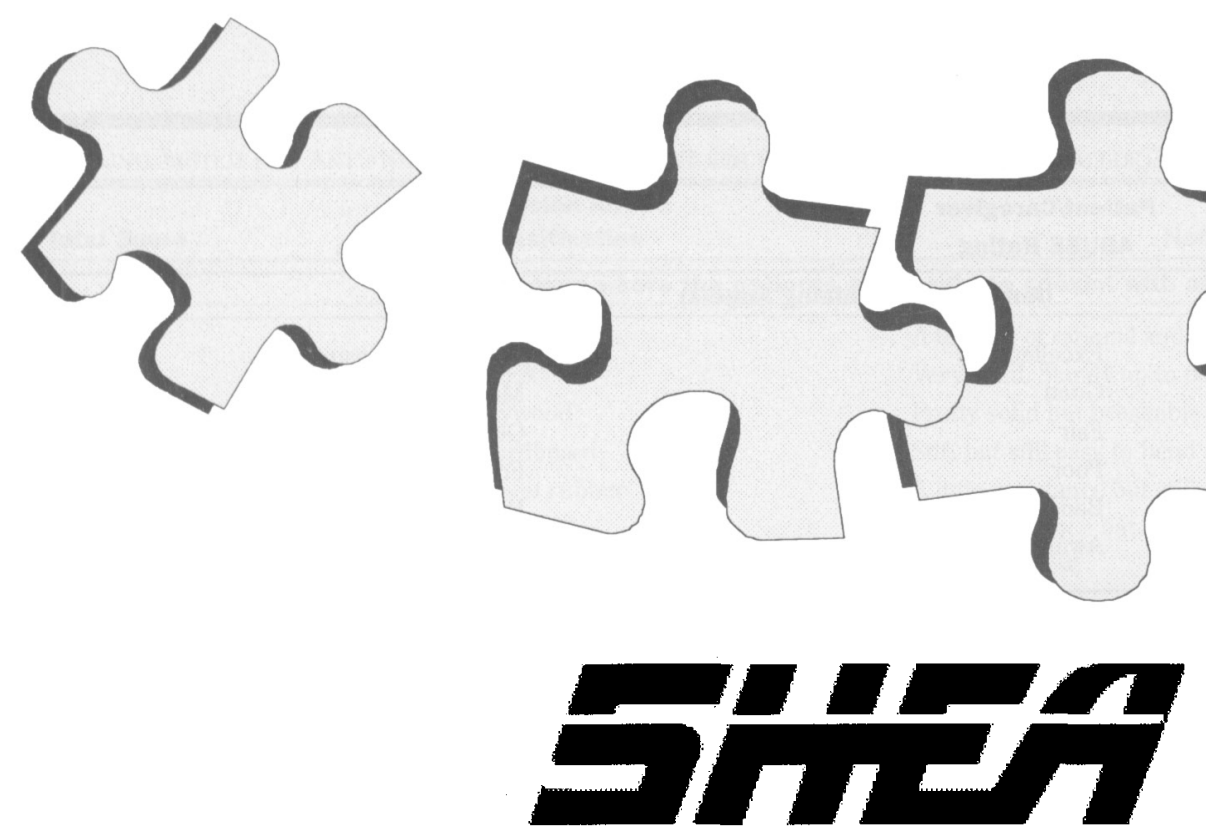

THE SOCIETY for HEALTHCARE EPIDEMIOLOGy of AMERICA

\section{Where do you fit in SHEA?}

SHEA was established to advance the study and application of hospital epidemiology-both traditional infectious disease epidemiology and non-infectious disease epidemiology as they relate to patient care, health care worker safety, quality improvement and outcomes research in and out of the hospital setting.

SHEA's primary goal is to educate members and improve their ability to be infection control and quality assurance practitioners. This is accomplished through our journal, Infection Control and Hospital Epidemiology, a series of position papers by experts in the field; annual scientific meetings; training courses in hospital epidemiology; industry surveys; and a state grassroots legislative network.

SHEA has more than 1200 members from 29 countries that are active in SHEA and in infection control in their own countries.

We welcome all qualified individuals working or interested in healthcare epidemiology.
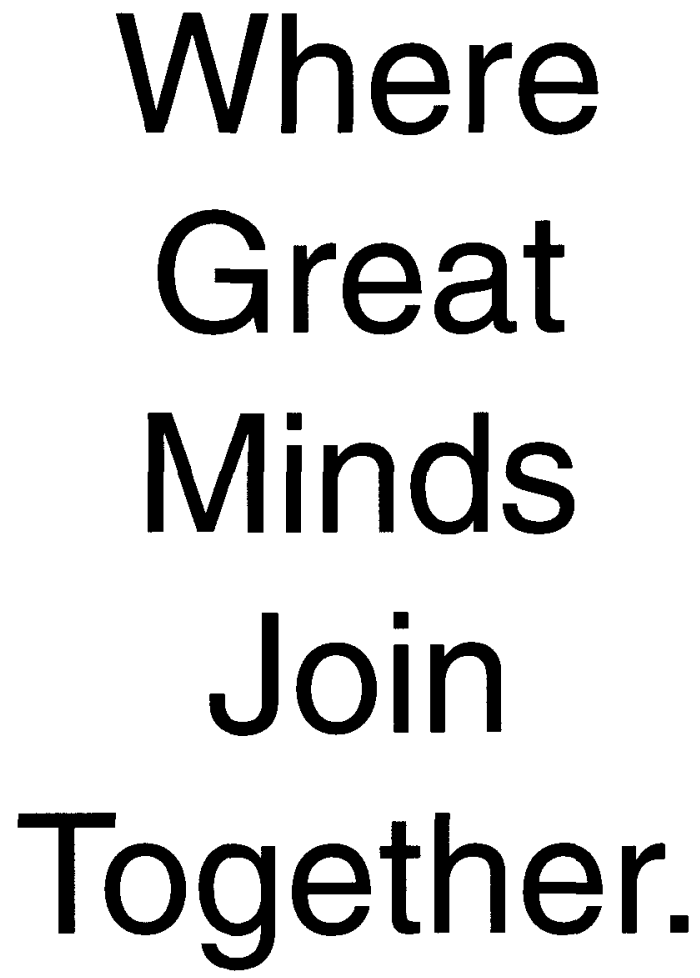

To inquire about becoming a member of SHEA, contact us today.

Phone: 856/423-0087

Fax: 856/423-3420

E-mail:sheahq@talley.com

Web site: www.shea-online.org

Mailing address: 19 Mantua Road, Mt. Royal, New Jersey 08061

\section{Smart membership benefits:}

As part of your SHEA membership, you will receive the following:

The society's official journalInfection Control and Hospital Epidemiology -at no charge. Non-members pay $\$ 109$ (U.S.) just for a subscription. That's the same price as annual membership dues in SHEA, which entitle you to yearlong benefits.

Access to the SHEA Web site, which includes position papers and data on salaries for healthcare epidemiologists and remuneration for part-time services in hospitals.

Reduced registration fees to annual scientific meetings and training courses.

Inclusion and access to the SHEA Membership Directory with more than 1200 member listings.

The opportunity to influence the field of healthcare epidemiology through participation on SHEA committees and boards. 